Historic, archived document

Do not assume content reflects current scientific knowledge, policies, or practices. 

United States

Department

of Agriculture

Forest Service

Intermountain

Research Station

Research Paper

INT-RP-494

December 1996

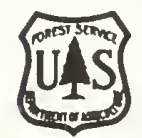

Localized Spatial and Temporal Attack Dynamics of the Mountain Pine Beetle in Lodgepole Pine

Barbara J. Bentz James A. Powell Jesse A. Logan

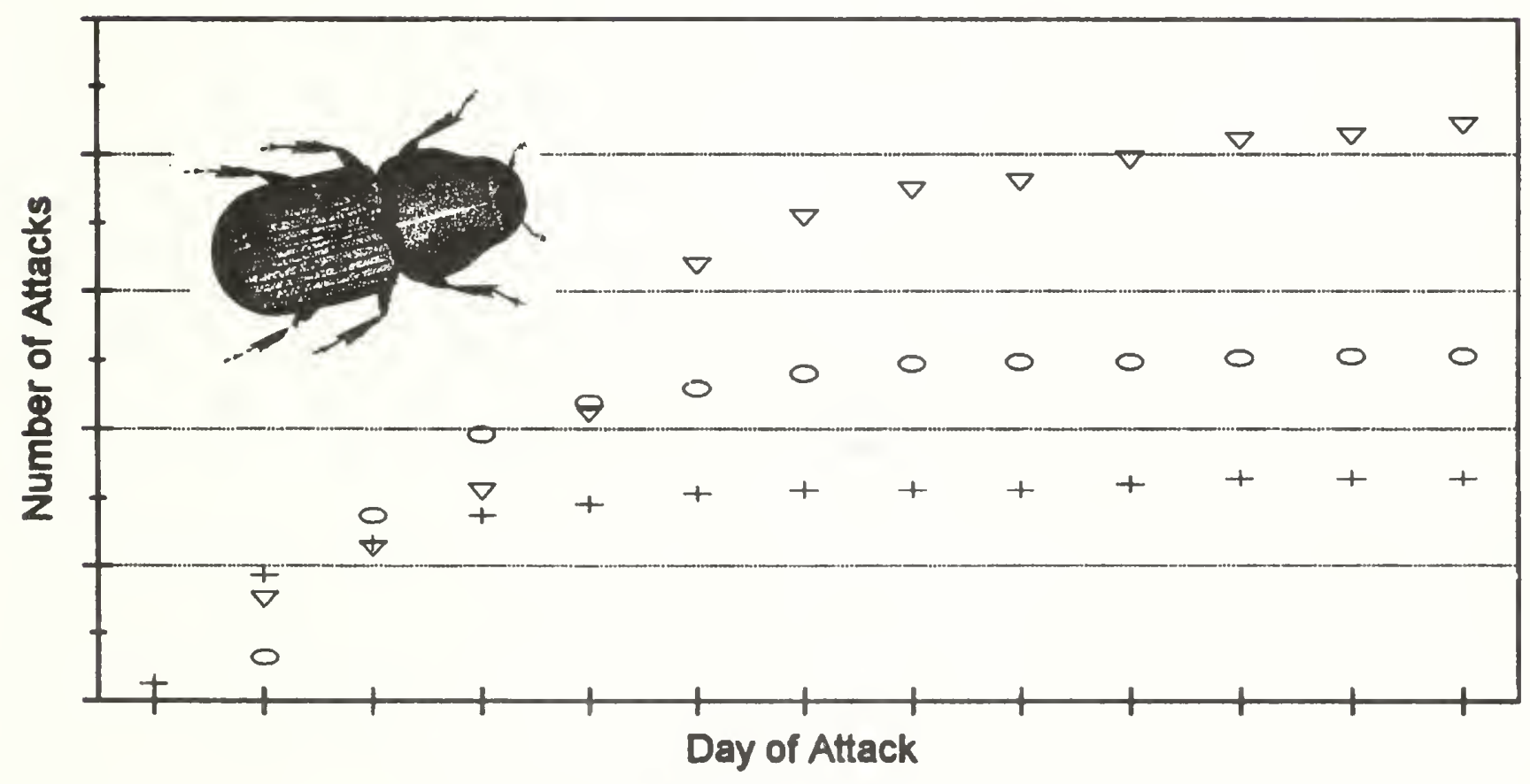

+ Baited $\nabla$ T1 0 T2 


\section{The Authors}

Barbara J. Bentz is a Research Entomologist with the Intermountain Research Station's Mountain Pine Beetle Project, and Assistant Professor (Federal Cooperator) in the Forest Resources Department at Utah State University. She received a Ph.D. degree from Virginia Polytechnic Institute and State University in 1991 and an M.S. degree from the University of Idaho in 1984.

James A. Powell is an Assistant Professor in the Mathematics Department at Utah State University. He received a Ph.D. degree in applied mathematics from the University of Arizona in 1990.

Jesse A. Logan is Project Leader for the Intermountain Research Station's Mountain Pine Beetle Project. He is also a Professor in the Forest Resources Department at Utah State University and Acting Director for the Center for Research on Disturbance Ecology, a joint venture between the Intermountain Station and Utah State University. He holds a Ph.D. degree in entomology from Washington State University, an M.S. degree in entomology from Colorado State University, and a B.S. degree in biology from Colorado State University.

\section{Research Summary}

Colonization of a host tree by the mountain pine beetle involves a complex, sýnergistic interaction between hostproduced chemicals and beetle-produced pheromones. This system of chemical communication enables a massive aggregation of beetles on a single resource, thereby ensuring host death and subsequent beetle population survival. Because a single host tree is a limited food and breeding resource, mountain pine beetle populations have evolved a mechanism for termination of colonization on a tree at optimal beetle densities, with a concomitant switch of attacks to nearby trees. Several hypotheses attempt to explain this pheromone-mediated phenomenon. In an effort to more fully understand the entire colonization process, we observed the daily spatial and temporal attack process of mountain pine beetles (nonepidemic) attacking lodgepole pine. Results from this preliminary study suggest that beetles switch attacks to a new host tree before the original focus tree is fully colonized, and that verbenone, an antiaggregating pheromone, may be acting within a tree rather than between trees.

\section{Acknowledgments}

The authors thank Ken Gibson, Dan Miller, and Ken Raffa for helpful reviews of the manuscript, and Bridget Kobe for technical assistance in the field. 


\title{
Localized Spatial and Temporal Attack Dynamics of the Mountain Pine Beetle in Lodgepole Pine
}

\author{
Barbara J. Bentz \\ James A. Powell \\ Jesse A. Logan
}

\section{Introduction}

Many species of bark beetles in the genus Dendroctonus (Coleoptera: Scolytidae) use kairomones and pheromones in the processes of host selection, attack, and colonization (Borden 1982; Wood 1972). Female mountain pine beetle ( $D$. ponderosae Hopkins), which in this species are usually responsible for initiating a new attack, bore into the bark and through a chemically mediated synergistic reaction with host chemicals, release trans-verbenol. Trans-verbenol is an aggregative pheromone attracting both sexes (Hughes 1973; Pitman 1971; Pitman and others 1968). At higher concentrations of trans-verbenol, higher proportions of males are attracted (Renwick and Vite 1970). Males produce exo-brevicomin, which at low concentrations primarily attracts females (Conn and others 1983), although it may inhibit beetles at higher concentrations (Borden and others 1987; Rudinsky and others 1974). This system of chemical communication enables a massive aggregation of individuals on a single "focus" tree that for species such as mountain pine beetle, is selectively advantageous in overcoming host defensive mechanisms. As with most herbivores, however, there is an optimal density range of individuals on an exhaustible food resource (Berryman and others 1985). If beetle densities on a single tree are too high, mortality can result from within-tree competition for limited breeding and feeding space.

Several hypotheses attempt to explain the termination of colonization on a single tree at optimal beetle densities. The first assumes that anti-aggregative or inhibitory pheromones such as verbenone and exo. brevicomin deter incoming beetles, thereby terminating additional attacks and ensuring that beetle attack density does not exceed the threshold for optimum brood survival (Borden and others 1987). Verbenone is a semiochemical produced by mountain pine beetles (Rudinsky and others 1974), through autoxidation of host terpenes, and by enzymatic conversion by yeasts (Hunt and Borden 1989). Based on this hypothesis, as verbenone is released, the majority of beetles are dispersed at some distance, switching attacks from the focus tree to adjacent recipient trees (Geiszler and others 1980).

A second hypothesis emphasizes the role of host resistance, citing cessation of resin exudation as the primary cause for termination of colonization on a particular tree (Raffa and Berryman 1983; Renwick and Vite 1970). As with the first hypothesis, attacks switch to adjacent trees once the focus tree becomes fully utilized-the difference lies in the roles of inhibitory pheromones and host-tree resins. In the second hypothesis, inhibitory pheromones are one component of a suite of territorial behaviors that in conjunction with a decrease in resin exudation, enable individual colonizers to maximize reproductive potential (Raffa and Berryman 1982, 1983). From this perspective, inhibitory pheromones are perceived and function at the local scale; attacks switch to neighboring trees because the focus tree has become fully colonized and resin exudation ceases. This role for inhibitory compounds is comparable to studies performed with $D$. brevicomis, wherein inhibitory compounds such as verbenone were postulated to function as short-range regulators of attack density rather than long-range inhibitors that indicate a fully colonized host (Beyers and others 1984).

A third hypothesis, labeled the "threshold model," assumes that as a tree is mass attacked, the high concentration of trans-verbenol being emitted in the local area causes incoming beetles to attack neighboring trees that are enveloped in the pheromone cloud (Coster and Gara 1968; Gara and Coster 1968; Geiszler and others 1980). A threshold level of transverbenol is necessary to cause landing and attack on adjacent trees.

The presence of inhibitory pheromones in the genus Dendroctonus is known (Hunt and others 1989; Libby and others 1985; Pitman and others 1969; Rudinsky and others 1974; Ryker and Yandell 1983). However, our lack of knowledge about the explicit function of these pheromones in mountain pine beetle community ecology is exhibited by confounding results in past research endeavors (see Amman and Lindgren 1995 for a review). It is unclear whether inhibitory pheromones 
such as verbenone have a shielding effect around the tree under attack and are the main cause of switching, or if their function is to regulate attacks once beetles are on or very near the tree surface, playing a more localized role in the switching process. If indeed verbenone has a shielding effect, unknown parameters include the size of the shielding plume and timing of its influence. The main objective of this study was to collect information on the spatial and temporal sequence of the mountain pine beetle switching process. Original motivation for the study was to obtain quantitative information for parameterization of a mathematical model of mountain pine beetle dispersal that includes chemical ecology and spatial interaction between beetles and host trees (Powell and others 1996). Data at the fine spatial and temporal resolution necessary for deriving model parameters were unavailable in published literature. In this study we did not measure pheromone emission, but rather the effect of pheromones on beetle behavior. Specifically, we asked several questions: (1) How long after attacks are initiated on a focus tree does switching to surrounding trees occur? (2) What is the distance from the initial focus tree within which surrounding trees are protected from beetle attacks (the shielding affect)? (3) What affect does tree diameter have on the switching process?

\section{Methods}

Three plots in lodgepole pine (Pinus contorta Douglas var. latifolia Engelmann) stands in the Gold Creek drainage of the Sawtooth National Recreation Area, ID, were selected. Species composition in the drainage is approximately 80 percent lodgepole pine and 20 percent Douglas-fir (Pseudotsuga menziesii [Mirb.]Franco) and subalpine fir (Abies lasiocarpa [Hook.] Nutt.). Currently there is a sub-epidemic mountain pine beetle population that has been slowly building during the last 4 to 5 years. All plots were at an elevation of approximately $2,073 \mathrm{~m}$, and at least $100 \mathrm{~m}$ apart. On August 6, 1995, a mountain pine beetle pheromone tree bait (Phero Tech Inc., Delta, BC, Canada) was placed on the north side of a single tree in each plot. Based on emergence data from a nearby experiment (Bentz 1995), beetle flight in the area had just begun. The bait was left on each focus tree for 24 hours, then removed. All trees within a radial distance of $10 \mathrm{~m}(20 \mathrm{~m}$ diameter) from the focus tree were monitored for beetle attacks until August 18 at which time colonization of trees within the plots had, for the most part, stopped. Attacks were tallied twice per day (approximately 8:00 a.m. and 5:00 p.m.), by height on the bole ( 0 to $1.2 \mathrm{~m}, 1.2$ to $1.8 \mathrm{~m}$, and 1.8 to $2.4 \mathrm{~m}$ ) and aspect of the bole (N, E, S, W) where the attack was located. An attack was counted once the nesting hole was initiated and resin or frass was noticed; landing rates were not included. Each entry was marked with a colored push pin, and later tallied. Because our intent was to monitor the "natural" attack process of mountain pine beetle on lodgepole pine, those trees attacked while the bait was on the focus tree were removed from data analysis. A stem map was developed for each plot including diameter of each tree at $1.5 \mathrm{~m}$ above the ground (d.b.h.).

\section{Results}

Due to a lack of attacks in plots 2 and 3, only results from plot 1 are reported (fig. 1). 'T1' represents the first tree in the attack process, and similarly, ' $\mathrm{T} 7$ ' is the

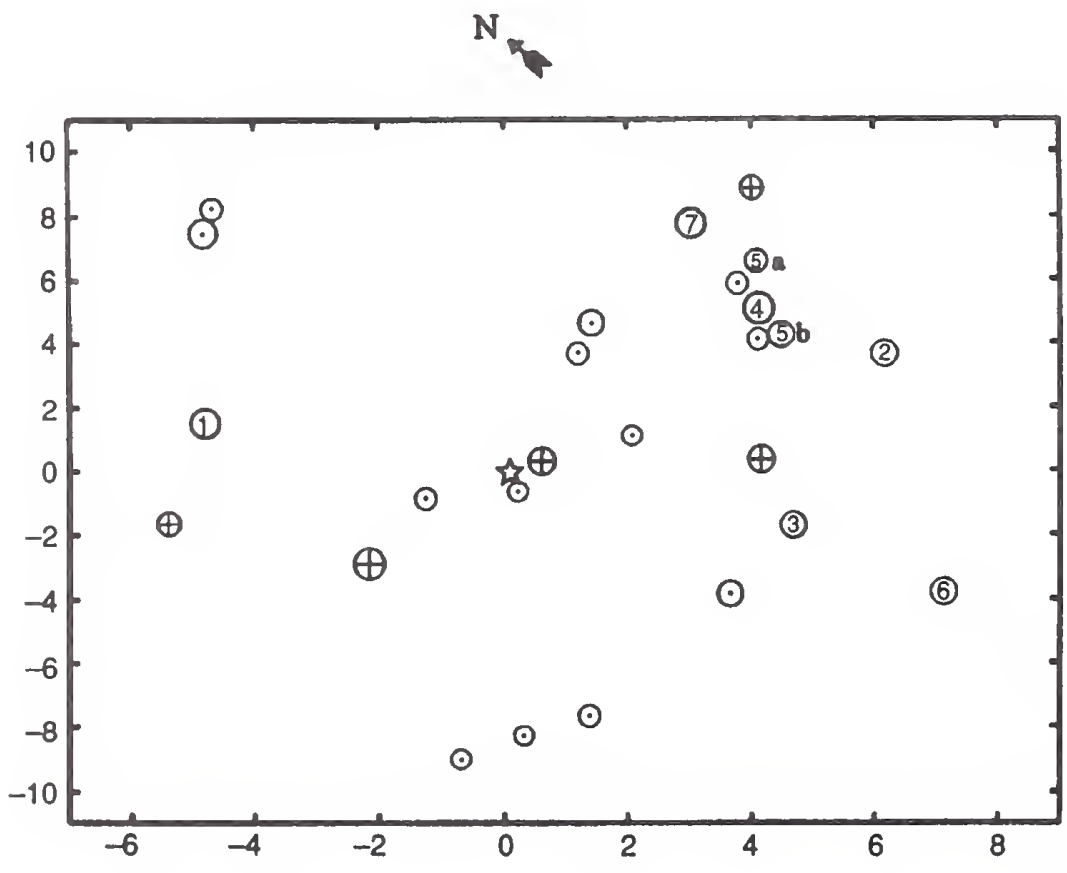

Figure 1-Spatial map (in meters) of all trees in plot 1. 1 is the baited tree at plot center, (1) are successfully attacked trees, with the number representing the day in the attack sequence, $\oplus$ are strip-attacked trees, and $\odot$ are live trees at the end of the attack period. Size of circle indicates relative diameter at breast height of each tree. 


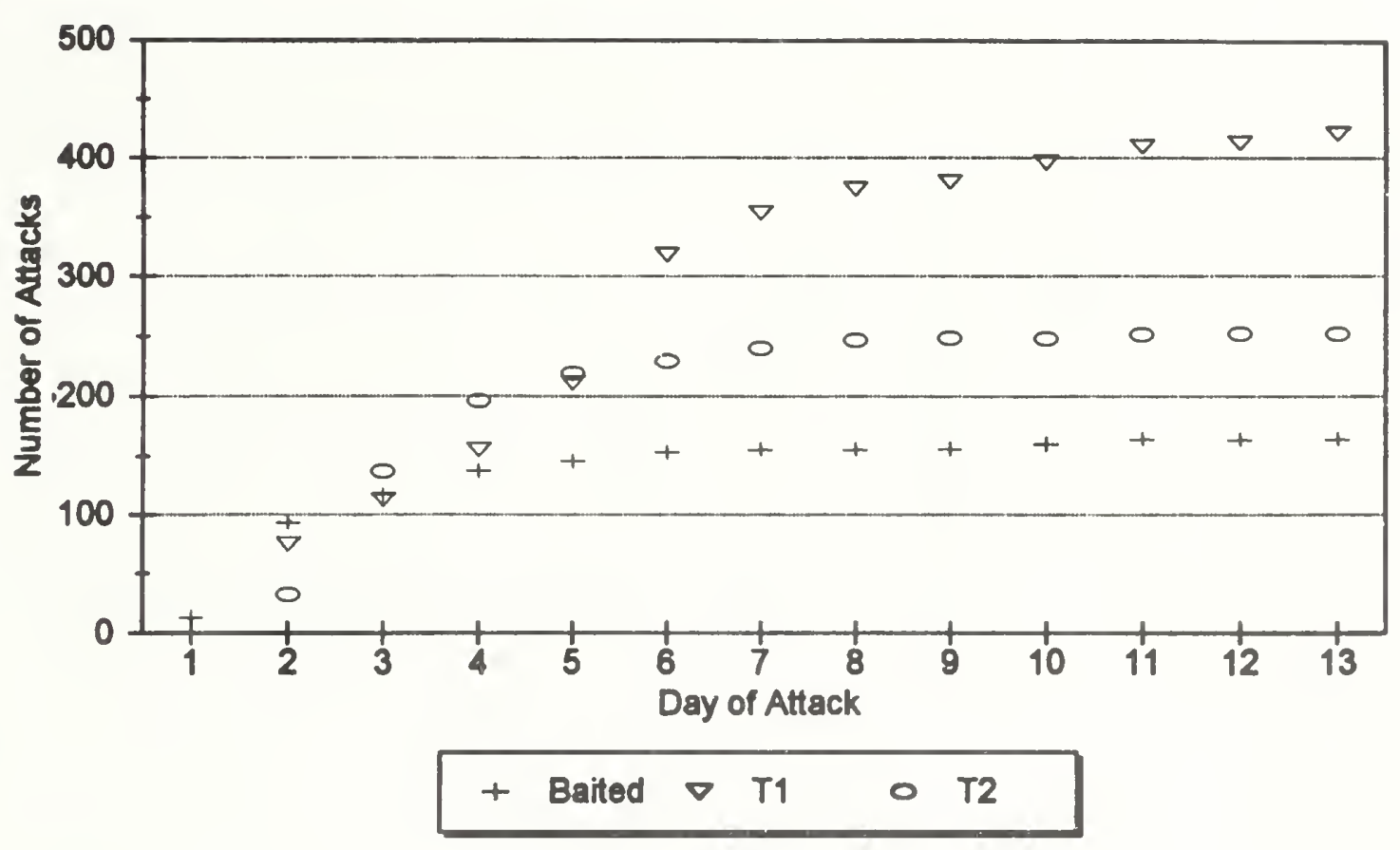

Figure 2-Cumulative number of attacks on the baited tree (Focus) and two additional trees in plot that were successfully attacked. Day 1 is August 6, 1995 (JD 218).

seventh tree attacked. Based on previous studies of attack behavior, we assume that attack density on the portion of bole sampled ( 0 to $2.4 \mathrm{~m}$ ) is representative of the whole tree. Rasmussen (1974) observed 79 percent of initial attacks below $2.1 \mathrm{~m}$, with a mean attack height of $1.4 \mathrm{~m}$. Others observed that attacks are initiated on the lower bole in a random fashion, with attacks filling in the remainder of the bole with time (McCambridge 1967; Reid 1963; Safranyik and Vithayasai 1971).

One day after removing the bait from the original focus tree, beetle attacks occurred on four trees in the plot; the closest attacked tree was a distance of $1.6 \mathrm{~m}$ from the focus tree. At that time, the focus tree had a greater number of attacks than any of the four surrounding trees. Of four trees attacked, only two were successfully mass attacked. A tree $0.58 \mathrm{~m}$ from the focus tree was attacked on day 1 , but because it was attacked prior to removing the bait it was removed from analysis. By day 3 , a tree $7.1 \mathrm{~m}$ from the focus tree had the greatest rate of attacks. Attacks on the original, baited focus tree peaked on day 2 , although it continued to receive at least a few attacks through day 7. Cumulative attacks on this tree did not level out until after surrounding trees had been attacked (fig. 2). This suggests that the switch in attacks to surrounding trees occurred prior to full utilization of the focus tree.
If we only consider those trees that were consecutively attacked from a nonbaited tree, a similar pattern is observed (fig. 1). On the day of peak attack density on T2 (day 3), new attacks occurred on T3. The following day, at peak attack density of T3, T4 was initially attacked (fig. 3). The next day, at peak attack density on T4, T5a, and T5b were attacked (fig. 4). In all cases, on the day when attacks switched to another tree, the proportion of attacks on the current focus tree was less than 45 percent (fig. 2,3 ). These results again suggest that attacks are redirected to a new tree prior to full utilization of the tree currently under attack. McCambridge (1967) observed that trees adjacent to the focus tree came under attack by mountain pine beetle before the initial focus tree had been fully mass attacked. Anderbrandt and others (1988) observed a similar pattern with Ips typographus Linnaeus. Geiszler and others (1980), however, reported that the switch to a new tree occurred after the original focus tree had been fully mass attacked. In our plot, tree spacing was closer than that reported in Geiszler and others (1980). Closest distance between consecutively attacked trees in our study was on day 5 between $\mathrm{T} 4$ and T5b, which were less than $1 \mathrm{~m}$ apart (fig. 1) Geiszler and others (1980) reported the closest recipient tree to be $3.6 \mathrm{~m}$ from the focus tree. Because it is impossible from our study design to say which trees were being switched from and to, we use the general 


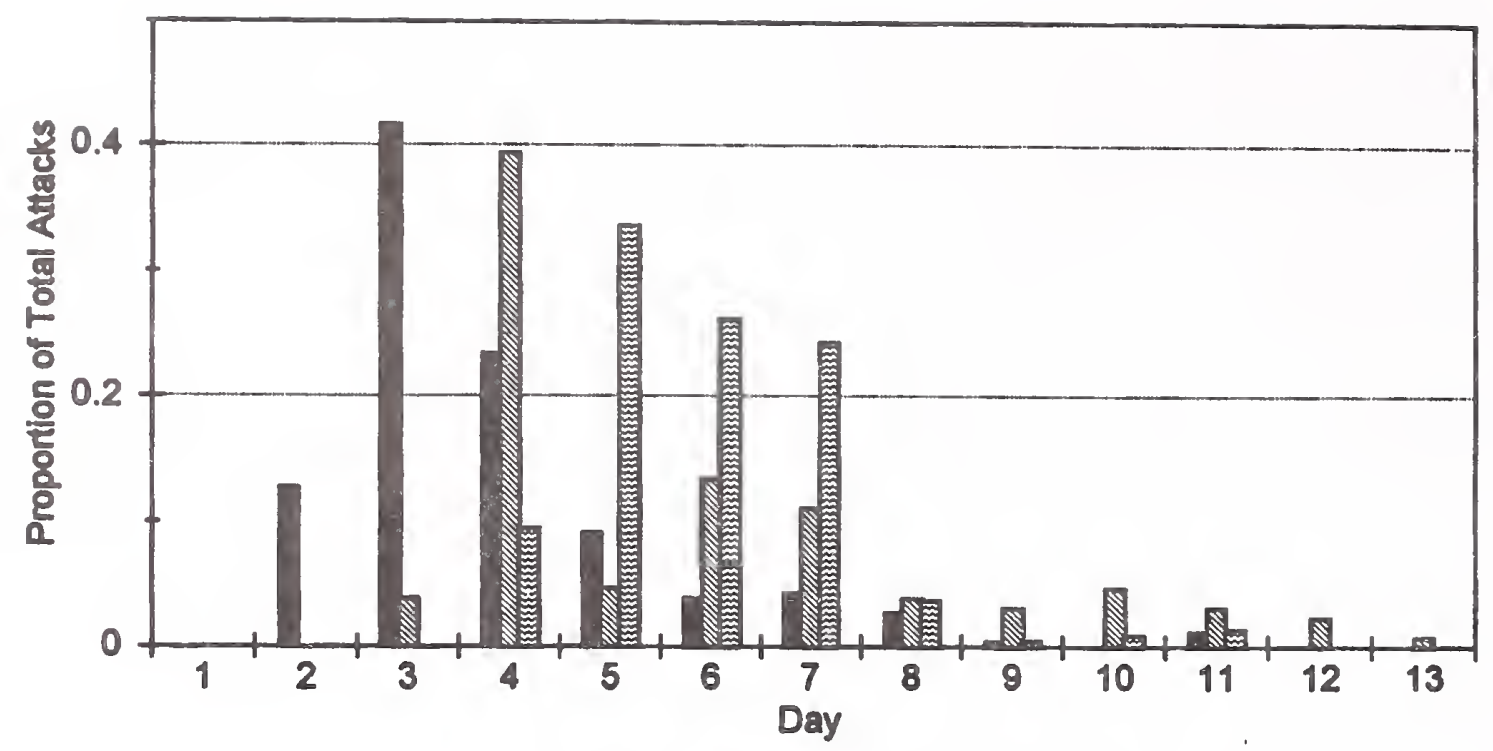

Figure 3-Proportion of total attacks on lower $2.4 \mathrm{~m}$ of bole of three trees that were successfully attacked, by day of attack. Day 1 is August 6, 1995 (JD 218).

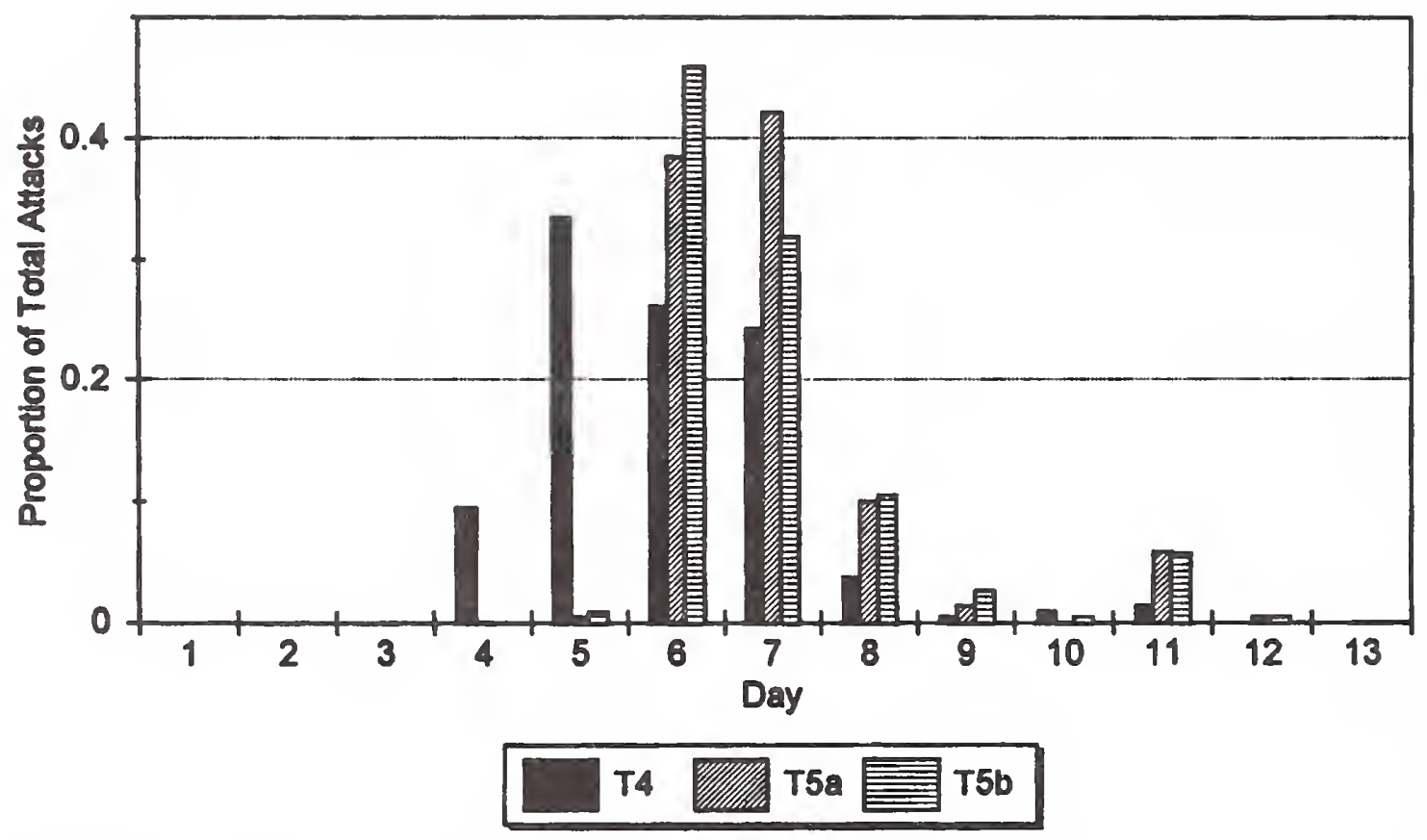

Figure 4-Proportion of total attacks on lower $2.4 \mathrm{~m}$ of bole of three trees that were successfully attacked, by day of attack. Day 1 is August 6, 1995 (JD 218). 
term "switch" to represent a shift in focus of attacks on consecutive days, regardless of distance. It is likely, however, that attacks are initiated on a single tree due to a cumulative affect of all trees in the local vicinity that are actively under attack. If our data are examined in this manner, it appears T6 may have been attacked by redirected beetles from T2 and T3, yet temporally further along than T6 in the mass-attack sequence (fig. 2, 5). In our study, except in one case, only one tree that was switched to on a particular day was successfully mass attacked, although many smaller trees were attacked at lower densities. Our study was in an area with a sub-epidemic population, however. Larger populations may behave differently.

Large trees are believed to initiate and maintain the switching process, while small trees are only killed because they are near other attacked trees (Geiszler and others 1980; Mitchell and Preisler 1991). Preisler and Mitchell (1993) found the probability that large trees are attacked to be greater than what a random attack model alone would predict. In our study, average d.b.h. of infested trees within the plot was 10.4 inches, strip attacked trees 9.5 inches, and remaining green trees 8.5 inches. These results indicate the mass attack process was initiated on larger trees more often than smaller ones. In fact, on day 5, attacks switched from T4 to T5a ( 8.5 inches d.b.h.) and T5b (9.6 inches d.b.h.), while a 7.6 inch d.b.h. tree closer to T4 had only a few attacks. This phenomenon could be due to either random landings on larger surfaces, or actual beetle preference for larger trees (Cole and Amman 1969; Gibson 1943; Hopping and Beall 1948). The largest distance between consecutively attacked trees (nonbaited) in our study was $3.2 \mathrm{~m}$, well within the maximum distance between attacked trees reported by others. Raffa and Berryman (1983) stated that no trees greater than $6 \mathrm{~m}$ apart were attacked, and Geiszler and others (1980) suggested no switching beyond $7.3 \mathrm{~m}$. Preisler and Mitchell (1993) found that in thinned stands, spacings of 4.3 to $6.9 \mathrm{~m}$ between trees did not seem to affect switching of attacks to surrounding trees.

If only those trees that were successfully attacked are considered, proportion of total attacks on the south aspect ( 28.2 percent) were slightly greater than either east (27.5 percent) or north ( 27.5 percent) aspects. West aspect of all trees had the lowest proportion of total attacks ( 16.7 percent). Typically beetles attack trees on the cooler north to east as pects; fewest attacks occur on hotter south aspects of the bole (Rasmussen 1974; Reid 1963; Safranyik and Vithayasai 1971; Shepherd 1965). However, in this study area, there was a nearby source of beetles to the south, and the plot was on a west-facing slope. Therefore, the south aspect may have been slightly cooler than west aspect, which may explain higher proportion of southern exposure attacks. Also, beetles may have taken advantage of upslope winds during the heat of the day. There

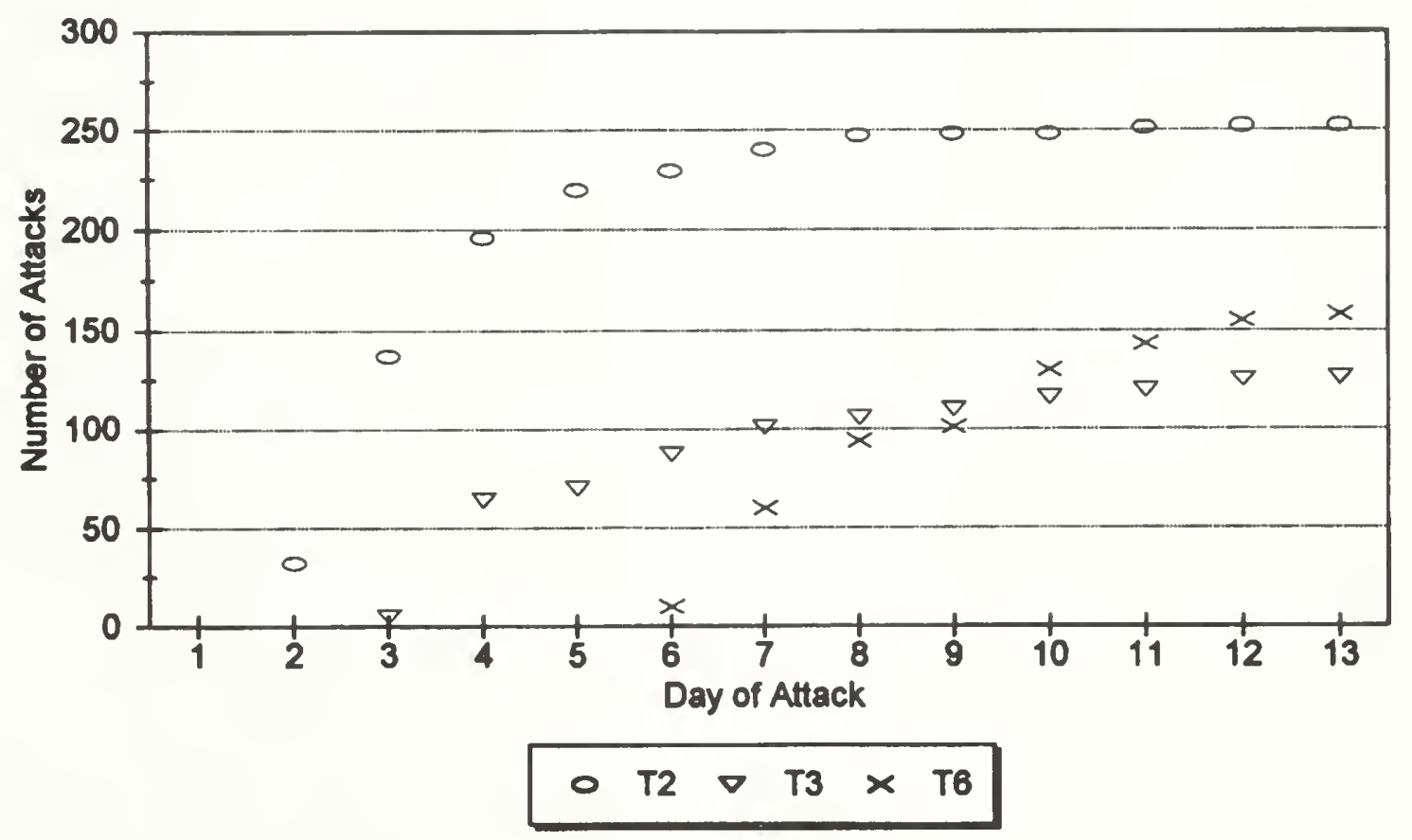

Figure 5-Cumulative number of attacks on three trees in plot that were successfully attacked. Day 1 is August 6, 1995 (JD 218). 
was no observable trend in a side of a tree initially attacked and direction of nearest attacked tree.

\section{Discussion}

We use the term "switch" to represent a shift in attacks on consecutive days between a focus tree and surrounding trees. In our study, switch in attacks from a focus tree to nearby trees typically occurred the second day of attack, and at time of peak daily attack density on the focus tree (fig. 3,4). Similarly, Raffa and Berryman (1983) observed highest rate of attack on day 2. Maximum attractiveness of the host coincides with the period of high trans-verbenol production; majority of production in female hindguts occurs after 24 hours of feeding (Pitman and Vite 1969). Female mountain pine beetle that had fed in lodgepole pine bolts for 24 hours also contained significant amounts of verbenone (Hunt and Borden 1989). Similarly, large amounts of volatiles of both verbenone and the aggregation pheromone (cis-verbenol) of Ips typographus were measured from individual entrance holes on the second day of attack (Birgersson and Bergstrom 1988). Large concentrations of both aggregation and inhibitory pheromones in the first few days of attack on a tree may cause mountain pine beetle to be attracted to the focus tree, and both space out on the bole and participate in the tree-switching mechanism (Bedard and others 1980; Birgersson and Bergstrom 1988). The function of inhibitory pheromones such as verbenone in this tree-switching mechanism is unclear, however.

Based on results of our study, shift in attacks to a new host occurred before the focus tree was fully colonized, although each tree continued to be attacked at a decreasing daily rate for 5 to 6 days. If beetles were responding to verbenone before landing on a tree, as suggested by Bertram and Paine (1994), range of perception in our study plot was smaller than the distance between the two closest trees attacked within a day (less than $1 \mathrm{~m}$ ). If verbenone was providing an inhibitory plume around a tree, most attacks on that focus tree would cease, signaling a fully utilized resource, although additional attacks may occur due to variability in the response threshold of individual beetles. However, because attacks shifted to a new tree while less than 50 percent of total attacks had occurred on the focus tree, verbenone (or other inhibitory pheromones) could be functioning at a more local scale, perhaps around a particular entrance hole, as was suggested previously (Raffa and Berryman 1983; Renwick and Vite 1970). While large amounts of aggregating pheromones are still being produced, verbenone may provide a means to reduce competition within a tree, while some other component of the pheromone system is the primary cause of attack switch to a new tree. The "threshold" hypothesis of Gara and Coster (1968) is supported by this reasoning.

Our results indicate that a shift in attacks to a new tree occurred on the day of greatest attack rate on a nearby tree. If we assume that time of greatest attack rate on a particular tree coincides with peak transverbenol emission from that tree, switch in attacks to a new tree could be explained by a spill-over effect. This would occur when the concentration of aggregation pheromone was large enough to envelope surrounding trees, resulting in random attacks on trees enveloped by the plume, and establishment of a new focus tree. The new focus tree then has an increase in number of attacks, while attacks on the old focus tree decline due to a reduction in attacks and concomitant trans-verbenol production (Pitman and Vite 1969). These results were seen in our data: number of attacks on recipient trees the first day of switching was always less than number of attacks on the focus tree that same day. The following day, attacks on recipient trees were greater than on the previous focus tree (fig. 3,4). Each beetle is more attractive when joined by other beetles than when alone, thereby resulting in the nonlinear increase in attacks with time observed. Throughout the 18 days we monitored the plot, many trees were under attack at the same time, resulting in overlapping plumes of aggregating pheromones. Although we have evaluated our data on a daily basis by looking at consecutively attacked trees, overlapping plumes of aggregation pheromones could become increasingly complex, greatly influencing beetles dispersing in the area. Although we do not know the size of aggregation pheromone plumes, our data suggests that the inhibitory, or antiaggregation, plume being released is smaller than the distance between two consecutively attacked trees spaced less than $1 \mathrm{~m}$ apart.

\section{Conclusions}

We have observed response of a nonepidemic population of mountain pine beetle to naturally occurring semiochemicals. Results from our study indicate that beetle attacks may switch to a new tree before the original focus tree is fully colonized. What role aggregation and inhibitory compounds play in the process of switching attacks to new trees, and the geographic extent of this phenomenon, are unclear. Because verbenone is used by so many species of aggressive bark beetles, and a large portion is produced by microorganisms in decaying wood, it may be a signal to beetles that the immediate substrate is no longer suitable for colonization (Borden and others 1987; Leufven and Birgersson 1987). The question remainsare beetles responding to verbenone prior to or after landing on the tree? Our results suggest that verbenone may be acting within a tree rather than between trees, 
and does not provide a very large inhibitory shield around the tree under attack. We concur with a previous hypothesis that suggests aggregation pheromone plumes larger than a single tree may be responsible for redirection of attacks, including some randomness, on a new tree. More research is necessary to more fully understand the behavioral sequence of the colonization process and spatial and temporal influence of inhibitory pheromone(s). Inconsistent results in attempts to apply inhibitory pheromones in a management scenario attest to insufficient knowledge of their full role in mountain pine beetle chemical ecology. Results from this preliminary study, however, provide important concepts necessary for linking our model of mountain pine beetle chemical ecology and dispersal (Powell and others 1996) to appropriate mountain pine beetle behavior observed in the field.

\section{References}

Amman, G.D., and B.S. Lindgren. 1995. Semiochemicals for management of mountain pine beetle: Status of research and application, pp. 14-22. In S.M. Salom and K.R. Hobson (eds.), Application of Semiochemicals for Management of Bark Beetle InfestationsProceedings of an Informal Conference, USDA For. Serv. GTR INT-318.

Anderbrandt, O., F. Schlyter, and J. Lofqvist. 1988. Dynamics of tree attack in the bark beetle Ips typographus under semiepidemic conditions, pp. 35-52. In T.L. Payne and H. Saarenmaa (eds.), Integrated Control of Scolytid Bark Beetles, Virginia Polytechnic Institute and State University.

Bedard, W.D., P.E. Tilden, K.Q. Lindahl, D.L. Wood, and P.A. Rauch. 1980. Effects of verbenone and trans-verbenol on the response of Dendroctonus brevicomis to natural and synthetic attractant in the field. J. Chem. Ecol. 6(6): 997-1013.

Bentz, B.J. 1995. Unpublished data, Intermountain Research Station, Logan Forestry Sciences Lab, Logan, Utah.

Berryman, A.A., B. Dennis, K.R. Raffa, and N.C. Stenseth. 1985. Evolution of optimal group attack, with particular reference to bark beetles (Coleoptera: Scolytidae). Ecology 66: 898-903.

Bertram, S.L., and T.D. Paine. 1994. Influence of aggregation inhibitors (verbenone and ipsdienol) on landing and attack behavior of Dendroctonus brevicomis (Coleoptera: Scolytidae). J. Chem. Ecol. 20(7): 1617-1629.

Birgersson, G., and G. Bergstrom. 1988. Volatile released from individual spruce bark beetle entrance holes. J. Chem. Ecol. 15(10): 2465-2483.

Borden, J.H. 1982. Aggregation pheromones, pp. 74-139. In Bark beetles in North American conifers. J.B. Mitton and K.B. Sturgeon (eds.), University of Texas Press, Austin.

Borden, J.H., L.C. Ryker, L.J. Chong, H.D. Pierce, B.D. Johnston, and A.C. Oehlschlager. 1987. Response of the mountain pine beetle, Dendrocton us ponderosae Hopkins (Coleoptera: Scolytidae), to five semiochemicals in British Columbia lodgepole pine forests. Can. J. For. Res. 17: 118-128.

Byers, J.A., D.L. Wood, J. Craig, and L.B. Hendry. 1984. Attractive and inhibitory pheromones produced in the bark beetle Dendroctonus brevicomis: Regulation of inter- and intra-specific competition. J. Chem. Ecol. 10: 861-877.

Cole, W.E., and G.D. Amman. 1969. Mountain pine beetle infestations in relation to lodgepole pine diameters. USDA For. Serv. Res. Note INT-95. Ogden, UT, 7 pp.

Conn, J.E., J.H. Borden, B.E. Scott, L.M. Friskie, H.D. Pierce, and A.C. Oehlschlager. 1983. Semiochemicals for the mountain pine beetle, Dendroctonus ponderosae, in British Columbia: Field trapping studies. Can. J. For. Res. 13: 320-324.
Coster, J.E., and R.I. Gara. 1968. Studies on the attack behavior of the southern pine beetle. II. Response to attractive host material. Contributions Boyce Thompson Inst. 24: 69-76.

Gara, R.I., and J.E. Coster. 1968. Studies on the attack behavior of the southern pine beetle. III. Sequence of tree infestation within stands. Contributions Boyce Thompson Inst. 24: 77-85.

Geiszler, D.R., V.F. Gallucci, and R.I. Gara. 1980. Modeling the dynamics of mountain pine beetle aggregation in a lodgepole pine stand. Oecologia 46: 244-253.

Gibson, A.L. 1943. Status and effect of a mountain pine beetle infestation on lodgepole pine stands. Mimeo. Rep., Forest Insect Laboratory, Coeur d'Alene, Idaho. $34 \mathrm{pp}$.

Hopping, G.R., and G. Beall. 1948. The relation of diameter of lodgepole pine to incidence of attack by the bark beetle Dendroctonus monticolae Hopkins. For. Chron. 24(2): 141-145.

Hughes, P.R. 1973. Dendroctonus: production of pheromones and related compounds in response to host monoterpenes. Zeitschrift fur angewand te Entomologie 73: 294-312.

Hunt, D.W.A., and J.H. Borden. 1989. Terpene alcohol pheromone production by Dendroctonus ponderosae and Ips paraconfusus (Coleoptera: Scolytidae) in the absence of readily culturable microorganisms. J. Chem. Ecol. 15(5): 1433-1463.

Hunt, D.W. A., J.H. Borden, B.S. Lindgren, and G. Gries. 1989. The role of autoxidation of $\alpha$-pinene in the production of pheromones of Dendroctonus ponderosae (Coleoptera: Scolytidae). Can. J. For. Res. 19: 1275-1282.

Leufven, A., and G. Birgersson. 1987. Quantitative variation of different monoterpenes around galleries of Ips typographus $(\mathrm{Co}$ leoptera: Scolytidae) attacking Norway spruce. Can. J. Bot. 65: 1038-1044.

Libby, L.M., L.C. Ryker, and K.L. Yandell. 1985. Laboratory and field studies of volatiles released by Dendroctonus ponderosae Hopkins (Coleoptera: Scolytidae). Z. Angew. Entomol. 100: 381-392.

McCambridge, W.F. 1967. Nature of induced attacks by the Black Hills beetle, Dendroctonus ponderosae (Coleoptera: Scolytidae). Ann. Entomol. Soc. Am. 60(5): 920-928.

Mitchell, R.G., and H.K. Preisler. 1991. Analysis of spatial patterns of lodgepole pine attacked by outbreak populations of the mountain pine beetle. For. Sci. 37(5): 1390-1408.

Pitman, G.B. 1971. Trans-verbenol and $\alpha$-pinene: their utility in manipulation of the mountain pine beetle. J. Ecol. Entomol. 64: 426-430.

Pitman, G.B., and J.P. Vite. 1969. Aggregation behavior of Dendroctonus ponderosae (Coleoptera: Scolytidae) in response to chemical messengers. Can. Entomol. 101(2): 143-148.

Pitman, G.B., J.P. Vite, G.W. Kinzer, and A.F. Fentiman. 1968 Bark beetle attractants: trans-verbenol isolated from Dendroc. tonus. Nature (London), 218: 168-169.

Pitman, G.B., J.P. Vite, G.W. Kinzer, and A.F. Fentiman. 1969. Specificity of population-aggregating pheromones in Dendroctonus. J. Insect Physiol. 15: 363-366.

Powell, J.A., J.A. Logan, and B.J. Bentz. 1996. Local projections for a global model of mountain pine beetle attacks. J. Theoretical Biol. 179: 243-260.

Preisler, H.K., and R.G. Mitchell. 1993. Colonization patterns of the mountain pine beetle in thinned and unthinned lodgepole pine stands. For. Sci. 39: 528-545.

Raffa, K.F., and A.A. Berryman. 1982. Gustatory cues in the orientation of Dendroctonus ponderosae (Coleoptera: Scolytidae) to host trees. Can. Entomol. 114: 97-104.

Raffa, K.F., and A.A. Berryman. 1983. The role of host plant resistance in the colonization behavior and ecology of bark beetles (Coleoptera: Scolytidae). Ecol. Monogr. 53(1): 27-49.

Rasmussen, L.R. 1974. Flight and attack behavior of mountain pine beetles in lodgepole pine of northern Utah and southern Idaho. USDA For. Serv. Res. Note INT-180. 7 pp.

Reid, R.W. 1963. Biology of the mountain pine beetle, Dendroctonus monticolae Hopkins, in the East Kootenay Region of British Columbia. III. Interaction between the beetle and its host, with emphasis on brood mortality and survival. Can. Entomol. 95: 225-238.

Renwick, J.A., and J.P.Vite. 1970. Systems of chemical communication in Dendroctonus. Contributions Boyce Thompson Inst. 24(13): 283-292. 
Rudinsky, J.A., M.E. Morgan, L.M. Libbey, and T.B. Putnam. 1974. Antiaggregative-rivalry pheromone of the mountain pine beetle, and a new arrestant of the southern pine beetle. Environ. Entomol. 3: 90-98.

Ryker, L.C., and K.L. Yandell. 1983. Effect of verbenone on aggregation of Dendroctonus ponderosae Hopkins (Coleoptera: Scolytidae) to synthetic attractant. Z. Angew. Entomol. 96: 452-459.

Safranyik, L., and C. Vithayasai. 1971. Some characteristics of the spatial arrangement of attacks by the mountain pine beetle, Dendroctonus ponderosae (Coleoptera: Scolytidae), on lodgepole pine. Can. Entomol. 103(11): 1607-1625.
Shepherd, R.F. 1965. Distribution of attacks by the Dendroctonus ponderosae Hopk. on Pinus contorta Dougl. var. latifolia Engelm. Can. Entomol. 97: 207-215.

Wood, D.L. 1972. Selection and colonization of ponderosa pine by bark beetles, pp. 101-107. In H.F. van Emden (ed.), Royal Entomological Society Symposium No. 6: Insect/Plant relationships. Blackwell Scientific Publications, Oxford, England. 
Bentz, Barbara J.; Powell, James A.; Logan, Jesse A. 1996. Localized spatial and temporal attack dynamics of the mountain pine beetle in lodgepole pine. Res. Pap. INT-RP-494. Ogden, UT: U.S. Department of Agriculture, Forest Service, Intermountain Research Station. 8 p.

Colonization of a host tree by the mountain pine beetle (Dendroctonus ponderosae) involves chemical communication that enables a massive aggregation of beetles on a single resource, thereby ensuring host death and subsequent beetle population survival. Beetle populations have evolved a mechanism for termination of colonization on a lodgepole pine tree at optimal beetle densities, with a concomitant switch of attacks to nearby trees. Observations of the daily spatial and temporal attack process of mountain pine beetles (nonepidemic) attacking lodgepole pine suggest that beetles switch attacks to a new host tree before the original focus tree is fully colonized, and that verbenone, an antiaggregating pheromone, may be acting within a tree rather than between trees.

Keywords: bark beetle, Dendroctonus ponderosae, pheromone, semiochemical

You may order additional copies of this publication by sending your mailing information in label form through one of the following media. Please specify the publication title and Research Paper number.

\author{
Telephone (801) 625-5437 \\ DG message Pubs:S22A \\ FAX (801) 625-5129, Attn: Publications \\ E-mail /s=pubs/ou1=s22a@mhs-fswa.attmail.com \\ Mailing Address Publications Distribution \\ Intermountain Research Station \\ 324 25th Street \\ Ogden, UT 84401
}

Federal Recycling Program Printed on Recycled Paper 


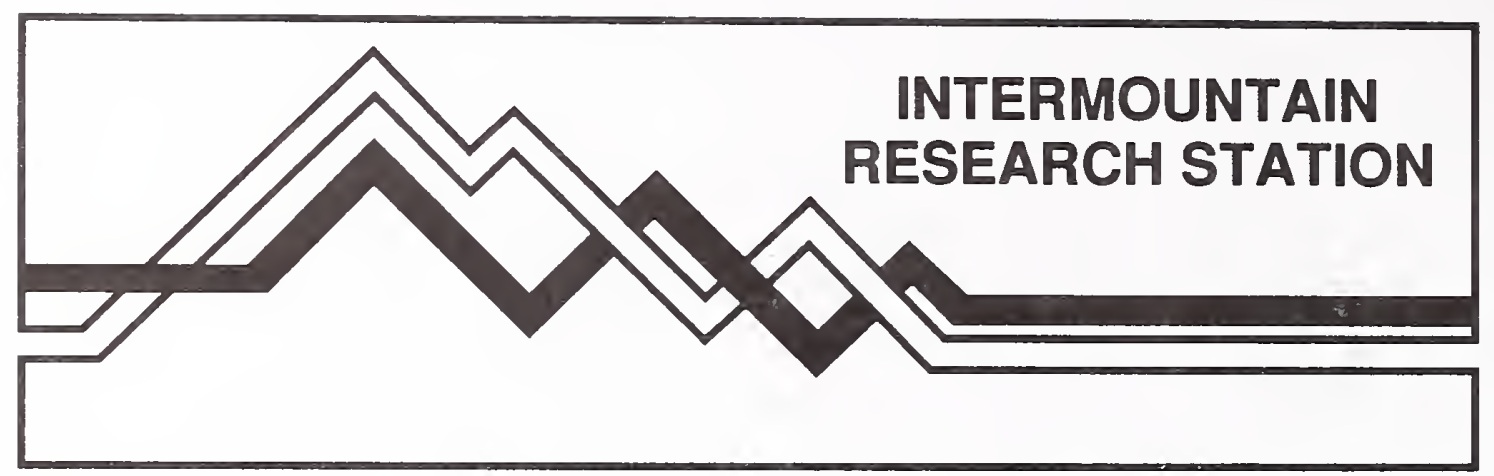

The Intermountain Research Station provides scientific knowledge and technology to improve management, protection, and use of the forests and rangelands of the Intermountain West. Research is designed to meet the needs of National Forest managers, Federal and State agencies, industry, academic institutions, public and private organizations, and individuals. Results of research are made available through publications, symposia, workshops, training sessions, and personal contacts.

The Intermountain Research Station territory includes Montana, Idaho, Utah, Nevada, and western Wyoming. Eighty-five percent of the lands in the Station area, about 231 million acres, are classified as forest or rangeland. They include grasslands, deserts, shrublands, alpine areas, and forests. They provide fiber for forest industries, minerals and fossil fuels for energy and industrial development, water for domestic and industrial consumption, forage for livestock and wildlife, and recreation opportunities for millions of visitors.

Several Station units conduct research in additional western States, or have missions that are national or international in scope.

Station laboratories are located in:

Boise, Idaho

Bozeman, Montana (in cooperation with Montana State University)

Logan, Utah (in cooperation with Utah State University)

Missoula, Montana (in cooperation with the University of Montana)

Moscow, Idaho (in cooperation with the University of Idaho)

Ogden, Utah

Provo, Utah (in cooperation with Brigham Young University)

Reno, Nevada (in cooperation with the University of Nevada)

The United States Department of Agriculture (USDA) prohibits discrimination in its programs on the basis of race, color, national origin, sex, religion, age, disability, political beliefs, and marital or familial status. (Not all prohibited bases apply to all programs.) Persons with disabilities who require alternative means of communication of program information (braille, large print, audiotape, etc.) should contact the USDA Office of Communications at (202) 720-2791.

To file a complaint, write the Secretary of Agriculture, U.S. Department of Agriculture, Washington, DC 20250 , or call 1-800-245-6340 (voice) or (202) 720-1127 (TDD). USDA is an equal employment opportunity employer. 